\title{
Mushroom Poisoning
}

\author{
Maj Salil Garg*, Lt Col Vasu Vardhan ${ }^{+}$, Air Cmde SC Sood
}

MJAFI 2003; 59 : 266-268

\section{Introduction}

$\mathrm{W}_{\mathrm{h}}$ ith the increasing influence of western dietary habits and advent of mushroom farming on a bigger scale, mushrooms are being used frequently in Indian diets. Normally the cases of poisoning are rare as commercially obtained mushrooms are grown under well-controlled conditions. It is when the gourmets become more adventurous and the so called experts start foraging for wild edible mushrooms that accidents occur as both the poisonous and the nonpoisonous varieties grow close together [1]. We are reporting three cases of mushroom poisoning which we came across recently.

\section{Case Report - 1}

A ten year old boy was brought with the history of having consumed a vegetable cooked with mushrooms and onions three days back. The father had plucked the mushrooms from a jungle, something that he used to do quite frequently. The entire family had consumed the vegetable together. The elder sister had developed pain abdomen and diarnhoea the next morning and succumbed the same evening. The mother died enroute while accompanying the boy. The patient had developed pain abdomen, vomiting and diarrhoea for the past two days and had become drowsy and irritable since the previous evening. The clinical examination revealed an averagely built and nourished male with no icterus, cyanosis or oedema. The chest and cardiovascular systems were normal while the abdomen had generalized tenderness but no organomegaly. Neurological examination revealed a drowsy patient with normal sized bilaterally reacting pupils, occasional fasciculations, depressed reflexes and extensor plantars. There was no associated cranial nerve deficit.

Patient was given a thorough gastric lavage and started on symptomatic treatment with activated charcoal and antibiotics in the form of Ampicillin and Amikacin, and Neostigmine and Atropine that were titrated against the heart rate and pupillary size and high doses of steroids. Investigations revealed a deranged liver function test with a serum bilinubin of $2 \mathrm{mg} \%$, SGOT-100IU/L, SGPT-196IU/L and prolonged prothrombin time (Test $1 \mathrm{~min} 5 \mathrm{sec}$ and control -13 secs). The other parameters including the renal parameters were within normal limits. In spite of this treatment the patient continued to deteriorate and developed large-scale fasciculations, seizures and haematemesis. He died approximately forty hours after admission.

\section{Case Report - 2 and 3}

The 18 year old brother and 65 year old father of the patient described as case one, were admitted on the morning the patient died. Both were symptomatic with diarrhoea, pain abdomen and vomiting for the past three days though to a lesser degree than the other members of the family. Clinical examination of case two revealed mild hepatomegaly and dilated sluggishly reacting pupils. The SGOT levels were raised to $210 \mathrm{IU} / \mathrm{L}$, and the SGPT was $240 \mathrm{IU} / \mathrm{L}$. The prothrombin time was increased to $1 \mathrm{~min}$ and $15 \mathrm{sec}$ when the control was $13 \mathrm{sec}$. ECG showed sinus bradycardia with occasional non-conducted beats and the USG abdomen revealed mild hepatomegaly. The other investigations were within normal limits.

Examination of the father revealed icterus and mild hepatomegaly. The other systemic and general examinations were within normal limits. Investigations revealed a serum bilirubin of $6 \mathrm{mg} \%$, SGOT - $150 \mathrm{IU} / \mathrm{L}$, SGPT - $180 \mathrm{IU} / \mathrm{L}$, an increased prothrombin time of $40 \mathrm{sec}$ with the control being $13 \mathrm{sec}$. Other biochemical parameters including the ECG were normal.

Both the patients were started on management with a gastric lavage and activated charcoal, followed by a continuous infusion of sodium penicillin in the dose of 250 $\mathrm{mg} / \mathrm{kg} /$ day (1 vial of $5 \mathrm{lac}$ units $=300 \mathrm{mg}$ of sodium penicillin), lnj Vit K, tab Silymarin (140 mg) 2 tid, tab cimetidine $1 \mathrm{bd}$, and tab Vit C - 2 tid. This treatment was continued for seven days and the patients gradually improved with the biochemical parameters returning to normal. sodium penicillin was stopped but silymarin was continued for a period of two months. Both the patients are under follow-up and are asymptomatic after six months.

\section{Discussion}

Most of the toxic varieties of mushrooms contain more than one of the following classes of toxins : monomethylhydrazines, cyclopeptides, ibotenic acid, psilocybin, coprine, muscarine, and unknown [2-4]. First an effort should be made to identify the particular mushroom responsible for the poisoning preferably with the help of a mushroom expert. The clinical syndromes of the patients are generally dependant upon the predominant toxin and are as under [5] :

Gastrointestinal-delayed onset : It is caused mainly by the Amanita and the Gyromitra groups and accounts

"Graded Specialist (Medicine), 168 Military Hospital, C/o 56 APO, ${ }^{+}$Classified Specialist (Medicine), Military Hospital, Dehradun, 'Dy PMO, Head Quarter Western Air Command, New Delhi. 
for more than $95 \%$ of the fatalities $[4,5]$. Out of these two, the fatalities caused by Amanita group that contains more amatoxins are more in number. Both types of mushrooms are found to contain two groups of poisons (i) phalloidin - heptapeptide responsible for the early symptoms of Amanita poisoning and (ii) the amanitotoxin - which inhibits RNA polymerase responsible for production of mRNA. Both groups of poisons affect cells with high turnover rates with symptoms generally appearing after a latent period of 6-12 hours. The minimum lethal dose for amatoxin is $0.1 \mathrm{mg} / \mathrm{kg}$ of body weight $(5-15 \mathrm{mg}$ of amatoxin is contained in about 15-20 dried Amanita caps which is sufficient to kill a healthy adult). After 24-48 hours of ingestion, patients present with gastro intestinal symptoms, jaundice, renal failure and coma [7]. Overall mortality is between $5-40 \%$.

The symptoms after ingestion of Gyromitra are milder and fatalities rarer. Management mainly comprises gastric lavage at the earliest, followed by gastro-duodenal aspiration. Activated charcoal may interrupt the enterohepatic circulation of toxins. Sodium penicillin given IV in the dose of $250 \mathrm{mg} / \mathrm{kg} / \mathrm{day}$ sterilizes the gut and reduces the GABA - producing intestinal flora, enhances glucuronidation and thus prevents severe encephalopathy. In cases of fulminant hepatic failure, an orthotopic liver transplant may be necessary. Other effective drug for mushroom poisoning is silymarin, which is an active constituent of milk thistle. In animals, it has been found to completely counteract the toxic effects of Amanita toxin if given within 10 minutes of ingestion and if given within 24 hours it prevents death and reduces liver damage [7]. Silymarin is thought to bind to toxins and interrupt the recirculation of amanitotoxins through antioxidation, inhibition of lipid peroxidation and enhanced glucuronidation. It is available in the tablet strength of $70 \mathrm{mg}$ and $140 \mathrm{mg}$ but no IV preparation is available in India. Other drugs which have been found useful but whose clinical efficacy has not been completely proven are $\alpha$-lipoic acid, Cimetidine and $\mathrm{N}$-Acetylcysteine.

In cases of Gyromitra poisoning, pyridoxal phosphate, the co-enzyme that catalyses the production of monomethylhydrazines when administered in the doses of $25 \mathrm{mg} / \mathrm{kg}$ IV is thought to be effective.

Autonomic nervous system-rapid onset (Muscarine poisoning): Caused by mushrooms of the genus lnocybe and Clitocybe containing muscarine, which bind to postsynaptic receptors producing an exaggerated cholinergic response within $30 \mathrm{~min}$ to two hours after consumption [5]. The symptoms are found to subside within 6-24 hours. Patients can be managed symptomatically with Atropine Sulphate given intravenously.

Coprine ingestion: The genera Coprinus atramentarius (Inky Cap mushroom) and Clitocybe claviceps contain coprine, which like disulfiram inhibits the metabolism of acetaldehyde. Coprine intoxication becomes apparent after ingestion of alcohol and may occur upto five days after the ingestion of mushrooms in susceptible individuals $[1,5]$. Patients present with tachycardia, tingling of face and trunk and hyperemia. The symptoms are self-limiting and subside within a few hours. Propranolol may be helpful.

Central Nervous System-rapid onset - (Ibotenic and muscimol intoxication): Patients present with obtundation, lethargy, agitation and hallucinations as well as seizures. Specific management is carefully selected on the basis of the symptoms through atropine, physostigmine and diazepam to control seizures [2,5]. Muscimol and ibotenic acid causing above are contained in Amanita muscaria (Fly Agaric) and $A$ pantherina (Panther Cap).

Indole intoxication : Euphoria and hallucinations, tachycardia and seizures develop within $30 \mathrm{~min}$ of ingestion. Deaths are extremely rare and seizures may respond to diazepam [2,5]. Psilocybin and psilocin causing above are found in mushrooms of the genus Psilocybe. Copelandia.

Gastrointestinal- rapid onset : Acute gastrointestinal symptoms that are generally self-limiting and respond to supportive therapy are caused by many mushrooms such as Green Gill (Chlorophy/l molybdites), Gray Pink gill (Entolama lividum and other associated genera [5].

In the present series the patients were managed with vigorous gastric lavage and activated charcoal, which form an essential part of the treatment, that cannot be overlooked even if the patients present late as a lot of undigested toxins may be removed. In the other two patients, who presented later, we used penicillin and silymarin, even though the patients presented late and may have had a milder poisoning. Though we could not identify the type of mushroom: it was thought to be from the Amanita group. The first case died; as at that time we did not have access to literature but in the other two cases we were able to halt the progression of liver damage and these two patients are asymptomatic under regular medical follow up.

\section{References}

I. Mushroom poisoning (editorial). Lancet 1980:2:351.

2. Goldfrank LR. Mushrooms : toxic and hallucinogenic. In : Goldfrank's Toxicologic Emergencies. $5^{\text {th }}$ ed. Appleton \& Lange, 1994:951-61.

3. Litovtz TL. Smilkstein M. Felberg L. 1996 annual report of the American Association of Poison Control Centres Toxic 
Exposure Surveillance System. Am \& Emerg Med $1997 ; 15(5): 447-500$.

4. Fienfeld DA, Mofenson HC, Caraccio T, Kee M. Poisoning by amatoxin containing mushrooms in suburban New Yorkreport of four cases. J Toxicol Clin Toxicol 1994;32(6):71521.

5. Stephen $C$, Aronoff. Nonbacterial food poisoning. In:Behrman RE, Kleigman RM, Jenson HB, editors. Nelson textbook of paediatrics. $16^{\text {th }}$ ed. Philadelphia : W.B. Saunders \& Co, 2000;2171-3.

6. Warden CR, Benjamin DR. Acute renal failure associated with suspected Amanita smithiana mushroom ingestions : a case series. Acad Emerg Med 1998 Eug;5(8):808-12.

7. Vogel G, Tuchweber B, Trost W. Protection by Silibinin against Amanita phalloides intoxication in beagles. Toxicol Appl Pharmacol 1984;73:355-62. 